\title{
Squamous Cell Carcinoma with Co-infection of Microsphaeropsis arundinis and Geotrichum candidum: A Rare Case Report
}

\author{
Nurul Athirahwanti Afany, Khairuddin Djawad*(D) \\ Department of Dermatology and Venereology, Faculty of Medicine, Hasanuddin University, Makassar, Indonesia
}

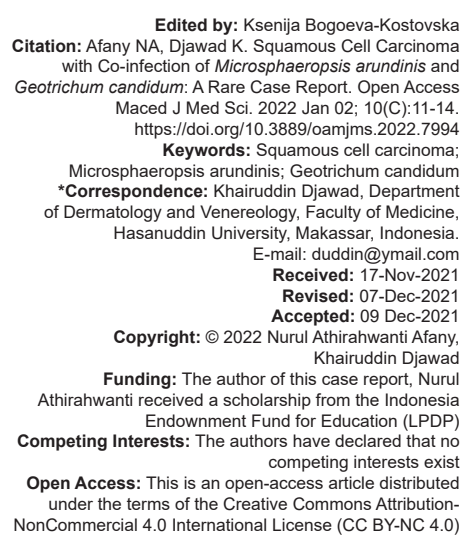

Edited by: Ksenija Bogoeva-Kostovska Edited by: Ksenija Bogoeva-Kostovsk
Citation: Afany NA, Djawad K. Squamous Cell Carcinoma with Co-infection of Microsphaeropsis arundinis and Geotrichum candidum: A Rare Case Report. Open Access Maced J Med Sci. 2022 Jan 02; 10(C):11-14 https://doi.org/10.3889/oamjms.2022.7994 Microsphaeropsis arundinis; Geotrichum candidum *Correspondence: Khairuddin Djawad, Departmen of Dermatology and Venereology, Faculty of Medicine, Hasanuddin University, Makassar, Indonesia. E-mail: duddin@ymail.com Revised: $07-$-Dec-2021 Revised: 07-Dec-202 Copyright: ๑ 2022 Nurul Athirahwanti Afany, Khairuddin Djawad

Funding: The author of this case report, Nurul Athirahwanti received a scholarship from the Indonesia
Endownment Fund for Education (LPDP) Competing Interests: The authors have declared that no Open Access: This is an open-access article distribis under the terms of the Creative Commons AttibutionNonCommercial 4.0 International License (CC BY-NC 4.0)

\begin{abstract}
BACKGROUND: Squamous cell carcinoma (SCC) is a non-melanoma skin cancer is a malignant carcinoma with an increasing incidence. The diagnosis of SCC is mainly based on clinical features and an excisional biopsy with histologic confirmation should be performed on all clinically suspected lesions to determine the prognostic and management of SCC. The first-line treatment of SCC of the skin is complete surgical excision. Microsphaeropsis arundinis and Geotrichum candidum are types of fungi that can infect the skin.

CASE REPORT: We report a case of a 46-year-old female patient that was diagnosed with SCC based on clinical dermoscopy, and histopathological features. In addition, M. arundinis and G. candidum were also found on culture examination, where these fungi are rarely found, especially in cases of SCC.

CONCLUSION: The patient underwent tumor excision and amputation.
\end{abstract}

\section{Introduction}

Squamous cell carcinoma (SCC) is a cancer arising from the proliferation of epidermal keratinocytes. It is the second most common skin cancer after basal cell carcinoma (BCC); however, its incidence is relatively rare on the feet, heels, and other areas that are not exposed to sunlight [1]. SCC accounts for approximately $20 \%$ of skin malignancies and $75 \%$ of all skin cancer deaths, excluding melanoma [2]. Verrucous carcinoma is a variant of SCC with deep invasion of the underlying local structures [3]. Verrucous carcinoma rarely metastasizes but can be locally invasive and destructive. If left untreated, Lesions can significantly enlarge. This carcinoma in the plantar area can be irregular, well-defined, verrucous, and is also known as epithelioma cuniculatum. Management is usually palliative and includes extensive and aggressive tumor resection [4].

Microsphaeropsis arundinis is a dematiacanamorphic fungus found in soil and freshwater. $M$. arundinis (fungi imperfecti) is a coelomycete that includes a new group of pathogens capable of causing soft tissue infections, mostly in immunocompromised human patients. The fungus usually penetrates the subcutis through trauma. The first reports of these organisms occurred more than 10 years ago [5]. Geotrichum candidum (teleomorph: Galactomyces candidus) is a dimorphic, ascomycetous species of the class Saccharomycetes. G. candidum is a commensal organism that can colonize one of them on the skin [6]. We report a case of a 46-year-old female patient with verrucous SCC with co-infection of $\mathrm{M}$. arundinis and $\mathrm{G}$. candidum that can lead to misdiagnosis and was treated with excision and subsequent referal to the orthopedic department.

\section{Case Report}

A 46-year-old female patient went to a dermatologist with complaints of mass and wound on the second and third fingers of the right foot for the past year. Initially, the patient had a history of moist feet that was covered by a white membrane. An enlarging mass that easily bled then appeared along with intermittent pruritus. The patient experienced pain especially if the lesion experienced friction. There is no history of fever and trauma. 


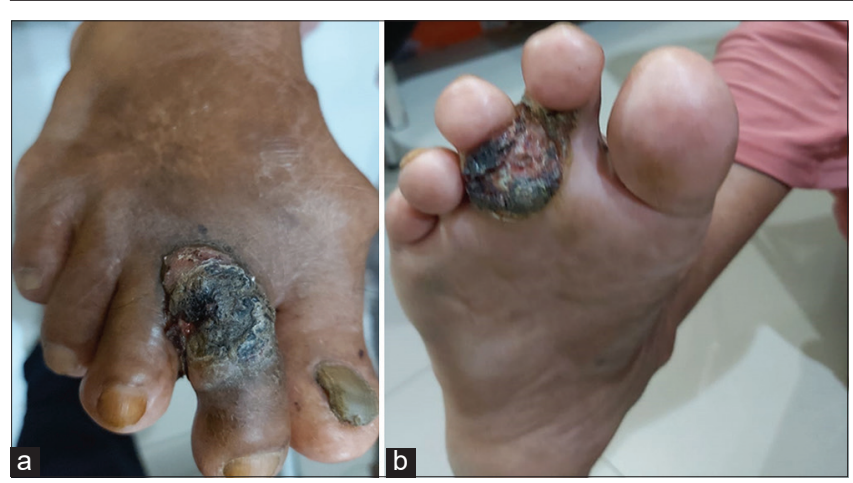

Figure 1: Clinical picture of the patient when she first came; (a) uppe right toe (from dorsum) lesion, (b) lower right toe (plantar) lesion

On physical examination, vital signs were within normal limits, and no enlarged lymphadenopathy was observed. On the $2^{\text {nd }}, 3^{\text {rd }}$ and $4^{\text {th }}$ digits of the right foot we found hyperpigmented verrucous nodule with the approximate size of $2.5 \mathrm{~cm} \times 3 \mathrm{~cm}$. Hyperpigmented plaque with thickness at around $2 \mathrm{~cm}$ was also found along with ulcers and crust (Figure 1). Dermoscopy found keratin/squama, blood spots, white structureless areas, and ulcerations (Figure 2).

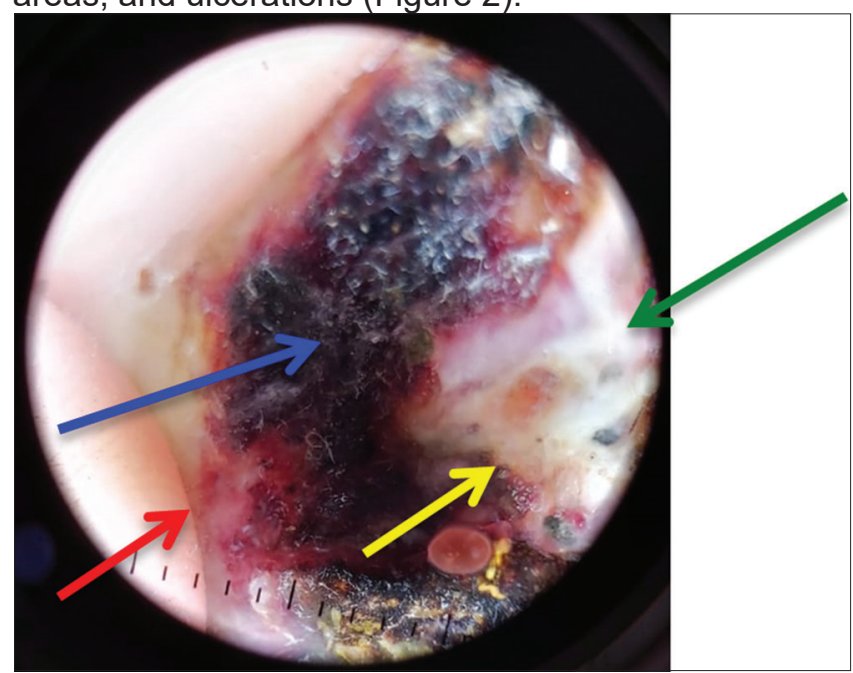

Figure 2: Dermoscopy of the lesion revealed keratin/scale (yellow arrow), blood spots (red arrow), white structureless areas (green arrow), ulceration (blue arrow)

The patient wassuspected with a diagnosis of SCC accompanied by a fungal infection, so histopathological examination and fungal cultures were performed. On histopathological examination, the conclusion that SCC is well differentiated (Figure 3). Fungal culture found $M$. arundinis and $G$. candidum (Figure 4). The patient was then referred to the orthopedic surgery department because of suspicion of bone invasion and surgical excision, as well as amputation, were performed.

\section{Discussion}

SCC is the second most common skin cancer after BCC. The incidence of SCC continues to increase

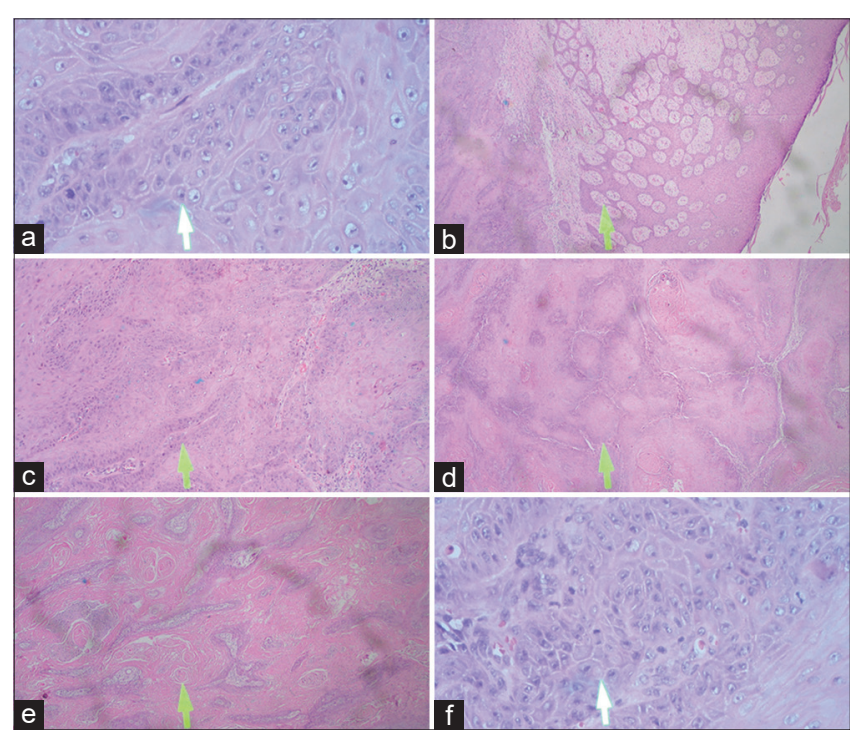

Figure 3: (a) Atypical nuclear squamous epithelial cell tumor nest, prominent nucleoli (40× magnification), (b) squamous epithelial cell tumor nest (4× magnification), (c) atypical nuclear squamous epithelial cell tumor nest, chaotic polarity with infiltrative growth (10x magnification), (d) squamous epithelial cell tumor nest $(4 \times$ magnification), (e) horn pearl (4× magnification), (f) atypical nucleus squamous epithelial cell tumor nest, pleomorphic, prominent nucleoli, chaotic polarity (40× magnification)

worldwide, with a reported increase of $50-200 \%$ over the past 3 decades. The incidence of SCC increases with age and is more likely to develop in chronically injured skin, including chronic ulcers, burn scars, and radiation dermatitis. Chronic inflammatory disorders of the skin and mucosal tissue can also predispose to SCC [7].



Figure 4: (a) Microsphaeropsis arundinis (macroscopic), (b) Geotrichum candidum (macroscopic), (c) Microsphaeropsis arundinis (microscopic), (d) Geotrichum candidum (microscopic)

Around $1 \%$ of skin cancers arise in chronically inflamed skin (e.g., burn scars, chronic ulcers, sinuses, 
inflammatory skin diseases) [1]. Verrucous carcinoma is a rare variant of SCC. Locations in the intertriginous region of the foot and bone invasion are rare. The etiology of verrucous carcinoma remains unclear, but as it can develop in areas of chronic inflammation, we suspect the lesion in our case is due to continuous maceration [8]. Macerated white membrane occurred one year prior that resulted in wound formation and possibly lead to SCC development.

The clinical manifestation of SCC varies and depends on the histologic subtype and the location of the tumor. Typical locations of verrucous SCC include the oral cavity, the genitoanal area, the plantar area, commonly referred to as the epithelioma cuniculatum [7]. The location of verrucous carcinoma in the interdigital is still very rare [8]. Dermoscopy examination was typical for invasive SCC, where we found keratin/scale, blood spots, white circles, white structureless areas, hairpin, and linear-irregular vessels, perivascular white halos, ulceration. Keratin/squama is a strong predictor of well-differentiated and moderately differentiated SCC, whereas the presence of blood vessels in more than half of the tumor surface with a diffuse distribution of blood vessels and bleeding was a predictor of poorly differentiated SCC [2].

The diagnosis of SCC was confirmed histologically. The superficial verrucous resembles a verruca with parakeratosis, acanthosis, and prominent stratum granulosum [7]. Histopathology of epithelioma cuniculatum showed hyperkeratosis, acanthosis with undulations, keratinization, well-differentiated squamous epithelium [2].

Interestingly, in our case, there was also the presence of fungal growth in culture that can lead to misdiagnosis. This was mentioned in a case report that found Candida parapsilosis in a SCC patient [9]. In addition, another case report mentioned seven patients. With SCC due to chronic chromoblastomycosis. The malignant lesions occurred independent of the antifungal therapy and all patients underwent curative amputation [10]. M. arundinis is a rare fungal infection in humans, and there have only been eight cases previously described in the literature. The clinical manifestations of $M$. arundinis are described in the literature as crusted indurated plaques that can be mistaken for other conditions such as SCC. Management of $M$. arundinis infection includes surgical excision, thermotherapy, and antifungal drugs including terbinafine, amphotericin, and azole antifungals such as itraconazole, posaconazole, and voriconazole [11]. There is still limited references regarding $M$. arundinis colonization in SCC lesions.

Geotrichum is a species of fungus that can be found in the environment and is abundant in soil, water, and in the air. In addition, it is also found in plants and dairy products, it has also been shown to be found in normal human flora (mucus and feces). G. candidum is mostly a saprophyte that can cause a disease called Geotrichosis [12]. G. candidum is a commensal organism that can colonize human skin, tracheobronchial tree, and digestive tract. It is rare to be pathogenic in human and is of low virulence. These organisms are usually acquired through ingestion or inhalation [6]. We have not obtained literature describing the presence of $G$. candidum in SCC lesions.

The management of SCC is either surgical or non-surgical [7]. This patient was consulted to the orthopedic department because of suspicion of bone invasion. In cases with difficult to distinguish borders, amputation may be performed, where complete excision of the tumor rarely results in recurrence [4]. The prognosis for verrucous carcinoma is generally good but local invasiveness and metastatic potential can occur [1].

\section{Conclusion}

The co-infection of $M$. arundinis and $G$. candidum in a patient diagnosed with SCC is a rare case and can lead to misdiagnosis. We hypothesize that the SCC lesion arised due to chronic inflammation caused by maceration. Treatment in this patient includes surgical excision and subsequent amputation.

\section{References}

1. Mansour O, Moussa MK, Raad RD, Zreik H, Allouch $A H$ Squamous cell carcinoma of the heel invading the calcaneus treated by radical excision and reverse sural flap. Cureus. 2020;12(9):e10740. https://doi.org/10.7759/cureus.10740 PMid:33145143

2. Fania L, Didona D, Di Pietro FR, Verkhovskaia S, Morese R, Paolino G, et al. Cutaneous squamous cell carcinoma: From pathophysiology to novel therapeutic approaches. Biomedicines. 2021;9(2):171. https://doi.org/10.3390/biomedicines9020171 PMid:33572373

3. Neville K, Obradovic A. Verrucous carcinoma arising secondary to diabetic foot lesions: A systematic review of the literature. SKIN J Cutan Med. 2021;5(3):228-32.

4. Knackfuss IG, Giordano V, Godoy-Santos AL, Fernandes NC Camargo OP. Squamous cell carcinoma in the foot: Case series and literature review. Acta Ortop Bras. 2018;26(2):108-11. https://doi.org/10.1590/1413-785220182602187183 PMid:29844733

5. Reppas G, Gottlieb T, Krockenberger M, Halliday C, Malik R. Microsphaeropsis arundinis: An emerging cause of phaeohyphomycosis in cats and people. Microbiol Aust. 2015;36:74-8.

6. Keene S, Sarao MS, McDonald PJ, Veltman J. Cutaneous geotrichosis due to Geotrichum candidum in a burn patient. Access Microbiol. 2019;1(1):e000001. https://doi.org/10.1099/ acmi.0.000001

PMid:32974489 
7. Hadaschik AS, Hadaschik EN. Squamous Cell Carcinoma and Keratoacanthoma. New York: Mc Graw Hill; 2019.

8. Rhizlane C, Sara E, Asmae R, Soukaina C, Zakia D, Hanane B, Fatimazahra $\mathrm{M}$, et al. A rare type and an unusual location of squamous cell carcinoma with bone invasion. PAMJ Clin Med. 2020;2:63. https://doi.org/10.11604/pamj-cm.2020.2.63.21376

9. Brothers RP, Daveluy SD. Squamous cell carcinoma mimicking fungal infection. IDCases. 2016;6:72-3. https://doi.org/10.1016/j. idcr.2016.09.016

PMid:27752471

10. Azevedo CM, Marques SG, Santos DW, Silva RR, Silva NF, Santos DA, et al. Squamous cell carcinoma derived from chronic chromoblastomycosis in Brazil. Clin Infect Dis. 2015;60(10):1500-4. https://doi.org/10.1093/cid/civ104

PMid:2568137

11. Nguyen $Y$, Dodds T, Lowe P. Cutaneous Microsphaeropsis arundinis infection in renal transplant recipients-a report of 2 cases and review of the literature. JAAD Case Rep. 2018;4(5):415-7. https://doi.org/10.1016/j.jdcr.2017.11.012 PMid:29984267

12. Bilman FB, Yetik M. Geotrichum candidum: A rare infection agent at urinary system and review of the literature. J Clin Exp Invest. 2017;8(4):127-9. https://doi.org/10.5799/jcei.382434 